Please refer to as:

Grimmelikhuijsen, S.G., Porumbescu, G., Hong, B., and Im, T. (2013). The effect of transparency in trust in government: a cross-national comparative experiment. Public Administration Review 73(4), 575-586.

\title{
A Cross-National Comparative Experiment on the Effect of Transparency on Trust in Government
}

Stephan Grimmelikhuijsen (Corresponding author)

Utrecht University, Utrecht School of Governance

Bijhouwerstraat 6.3511 ZC Utrecht, the Netherlands.

s.g.grimmelikhuijsen@uu.nl

Gregory Porumbescu (gporumbescu@gmail.com), Boram Hong (gertrudehong@ gmail.com), and Tobin Im (tobin@snu.ac.kr)

Seoul National University, Graduate School of Public Administration.

Seoul National University, Shilim-dong, Kwanak-gu.

Seoul, South Korea, 151-742 


\begin{abstract}
Transparency is considered a key value for trustworthy governments. However, the effect of transparency on citizens' trust across different national cultures is overlooked in current research. This article compares the effect of transparency on trust in government between the Netherlands and South Korea. The effect is investigated by two similar series of three experiments. We hypothesize that the effect of transparency differs, because both countries have different cultural values regarding power distance and short and long-term orientation. Results reveal similar patterns in both countries: transparency has a subdued and sometimes negative effect on trust in government. However, the negative effect in South Korea is much stronger. This implies a subdued and negative effect of transparency on trust in the short term in both countries. Nevertheless, the difference in the magnitude of transparency's effect suggests that national cultural values play a significant role in how people perceive and appreciate government transparency.
\end{abstract}




\section{Introduction}

Government transparency is seen by many as one of the keys to better governance. It can help prevent corruption, contribute to legitimacy, enhance government performance by increasing efficiency, and promote principles of good governance (e.g. Florini 1998; Birkinshaw 2006; Hood 2006; Roberts 2006). Moreover, government transparency is seen not only as a means to achieve certain goals, but has become a goal in itself. According to some transparency should even be viewed as a basic human right (i.e. "the right to know", Birkinshaw 2006).

The emergence of the ICTs and later the Internet has given rise to new possibilities for transparency: information can be stored and disseminated more easily by government. Furthermore, government information can now be read by anyone with access to the Internet; independent of time or place. This gave rise to a particular form of transparency: computermediated transparency (Meijer 2009). ICTs have catalyzed the spread and permeation of (government) information and eventually transparency practices throughout government. Although Freedom of Information Laws form the backbone for government transparency, computer-mediated transparency is an essential part of modern day government transparency.

Transparency is now proposed as the solution to one of the most intangible problems of democratic governance: citizens' increasing mistrust of government. Several authors argue that increased citizen knowledge of government processes and performance will increase understanding and trust in government (Bok 1997; Cook et al. 2010). This alleged positive effect of transparency on trust in government is extensively debated in the literature. As suggested above, optimists argue that transparency creates a culture of openness within government organizations which will strengthen citizen trust (Hood 2006, 217). On the other hand, skeptics stress that more transparency can elicit uncertainty and confusion among the 
public (O’Neill 2002). Other scholars emphasize that transparency might have no effect at all, because other determinants of trust in government are more important (e.g. Roberts 2006, 119). Recent empirical research shows that the positive effects of transparency on trust in government are limited at best (Tolbert and Mossberger 2006; De Fine Licht 2011; Grimmelikhuijsen 2012).

However, studies on transparency overlook the effect of cultural differences between countries on how transparency is viewed and related to citizen attitudes. Accounting for the influence of national contexts on the relation between transparency and citizens attitudes toward government is significant, as recent work has suggested that citizens' predispositions towards government in general influences the way government actions are perceived by the public (Bouckaert and Van de Walle 2003; Grimmelikhuijsen and Meijer 2012). General predispositions of people are determined by individual factors, such as education, age and political preference, and many studies have been carried out showing the influence of individual characteristics on (transparency and) trust (e.g. Nye et al. 1997; Putnam 2002). Nevertheless, to our knowledge no studies looked at the effect of transparency from a cultural perspective. National culture is an important driver for the way people think and act in any given society (Hofstede 2001). To fill this dearth in our knowledge, this article seeks to assess the influence of national culture on the relation between transparency and trust. The following research question will be central:

"To what extent does a country's national culture affect the relationship between transparency and trust in government organizations?" 
This paper combines a cross-country comparison with an experimental design. The crosscountry comparison will be used to compare the influence of national culture in each country. Hofstede's work on national culture will be used as a framework for assessing national culture in the Netherlands and South Korea. According to Hofstede's framework, both countries contrast strongly on important cultural characteristics. To investigate the effect of transparency on trust in both countries, a similar series of three experiments have been carried out in South Korea and the Netherlands, in order to compare transparency's effect

An experiment is particularly useful to assess the actual causal effect of transparency on trust instead of mere correlation. Several groups of people are presented with different degrees and types of transparency, and afterwards their trust levels are measured by means of a questionnaire. By carrying out experiments, an empirically founded and more refined view on causal relationships between transparency and trust in government can be provided. Each experiment tests the effects of one type of transparency: decision-making transparency, policy information transparency and policy outcome transparency. First the two core concepts of the research question - transparency and trust - will be specified first.

\section{Defining Transparency and Trust}

\subsection{Defining Transparency}

Most definitions of transparency relate to the extent to which an entity reveals relevant information about its own decision processes, procedures, functioning and performance (Gerring and Thacker 2004; Welch, Hinnant, and Moon. 2005; Curtin and Meijer 2006). As such, transparency typically incorporates multiple components including the availability of information about the internal workings or performance of an organization. This enables 'inward observability', which refers the ability of individuals and groups outside of the 
organization to monitor activities and decisions undertaken within the organization. This leads to the following definition: Transparency is the availability of information about an organization or actor allowing external actors to monitor the internal workings or performance of that organization.

In this paper we will specifically focus on computer-mediated transparency (cf. Meijer 2009). How to measure computer-mediated transparency in an experimental setting? This article focuses on three different qualities of transparent information: completeness, color and usability. Although these three characteristics are by no means exhaustive and do not capture the full complexity of all features of transparency, these are considered central in many discussions about transparency and are therefore central to this study.

Information completeness refers to whether the information is disclosed fully (i.e. its comprehensiveness). Moon and Norris (2005) refer to transparency as the amount of information available on official government websites. However, completeness of information should not be equated to amount. For instance, government organizations that overload citizens with a huge number of inaccurate policy reports might be considered less transparent than those with concise yet accurate content.

The color of information refers to the degree of positiveness of the information. Scholars seem to agree that information on government websites tends to be overly positive about government actions or officials (Davis 1999; Etzioni 2010, 398; Porumbescu 2013). As such, in this study the extent to which information is colored by a politically favorable interpretation of the truth is the second central dimension of information.

The third major element in determining the degree of computer-mediated transparency is the usability of information on a website. Instead of just divulging more 
information, the way information is offered to the public is also important. For instance, transparency also implies that information is disclosed in a timely matter and presented in an understandable format (Larsson 1998; Dawes 2010).

In terms of its object, transparency concerns separate events and processes of government (cf. Heald 2006; Grimmelikhuijsen and Welch 2012): 1) transparency of decision making processes; 2) transparency of policy content; and 3) transparency of policy outcomes or effects. ${ }^{1}$

Decision-making transparency concerns the degree of openness about the steps taken to reach a decision and the rationale behind the decision. Democratic decision-making transparency has traditionally been a cornerstone of accountability. This provides citizens with relevant information about decisions that affect them, and allows them to check whether these decisions are in line with acceptable norms or election promises. Open meetings and open minutes of parliamentary meetings are examples of forms of decision-making transparency. The critical aspect of transparency in decision-making relates not to the decision itself; decision-making transparency is especially relevant to make visible how the process of decision-making went, in this way the public is allowed to assess why the decision outcome was the way it was. This study specifically focuses on this aspect of decisionmaking transparency.

Policy transparency refers to the information disclosed by government about the policy itself: what the adopted measures are, how they are supposed to solve a problem, how they will be implemented and what implications they will have for citizens and other affected groups. For example, many government organizations have websites on which they present their policy plans containing proposed measures to combat pressing problems such as 
pollution or crime. The actual policy is the outcome of a decision-making process, and hence policy transparency might be considered to follow from decision-making transparency.

Policy outcome transparency captures the provision and timeliness of information about policy effects. For example, it could show a city’s crime rates or disclose pollution data. The importance of policy outcome transparency has been catalysed by the growing emphasis of NPM-like reforms on policy results (Pollitt and Bouckaert 2004). Further, policy outcomes primarily regard the effect of the policy measures that have been carried out. Therefore policy outcome transparency is considered to follow from policy transparency.

In this article three objects of transparency (decision-making, policy, and policy outcome) and three dimensions of information (completeness, color and usability) will be tested. In order to gain a deeper understanding of transparency, this multidimensionality will be used to measure transparency more accurately (see section 5, the Method section, for information on measures of these dimensions).

\subsection{Defining and Measuring Trust in Government}

This article focuses on institutional trust (e.g. Zucker 1986; Cook and Gronke 2005), but tries to connect this to the general literature on trust. Trust is a nebulous concept and has been a central object of study for decades in many disciplines. Understanding why and how people trust has thus been the central focus of research for psychologists, sociologists, political scientists, economists and organisational scientists. In order to fully understand trust in government, we need to have an inter-disciplinary understanding of trust. However, across and even within disciplines, a myriad of definitions, concepts and operationalizations are being used in research. Because of this pluralism, Rousseau, Sitkin, Burt, and Camerer (1998) developed a cross-disciplinary definition of trust that is frequently cited in the social sciences: 
Trust is 'a psychological state comprising the intention to accept vulnerability based upon positive expectations of the intentions or behavior of another.' (Rousseau et al. 1998, 395)

According to Rousseau and colleagues, all definitions of trust are premised upon the presence of some form of positive expectation regarding the intentions and behavior of the object of trust (Yamagishi and Yamagishi 1994; Kramer and Lewicki 2010). In the context of this study, positive expectations can be thought of as perceptions of the trustworthiness of government. Trustworthiness refers to the characteristics of the object of trust as perceived by an individual (Kim 2005). A large body of literature has attempted to identify specific elements that might influence an individual's perceptions of trustworthy behaviors and intentions. Generally, the importance of the various elements tends to differ according to the discipline in question, for the reason that the object of trust often differs according to discipline. Nevertheless, in spite of the diversity in terms of elements argued to influence perceptions of trustworthiness, some degree of commonality can be found (Rousseau et al. 1998). To this end, although several differences exist among scholars regarding the elements said to influence perceptions of trustworthiness, all elements tend to converge into distinct dimensions. These dimensions, which are held in common are discussed below.

First, all authors find some form of competence to be a part of trustworthiness. Some call it effectiveness (Hetherington, 1998) or expertise (Peters, Covello and McCallum 1997). Yet the differences in meaning are subtle, so it should be clear that some evaluation of government performance is part of its trustworthiness.

Further, nearly all authors regard benevolence as a part of trustworthiness. This can be viewed as an ethical dimension of trustworthiness, as it particularly focuses on the intention 
of government action. Some authors call this dimension care (Peters et al. 1997) or commitment (Levi and Stoker 2000). It expresses some kind of interest by one being trusted by those other than themself. Benevolence might be the term that best fits with this study's object of trust, namely government organizations. A government organization that genuinely cares about the citizens it is serving would most likely be perceived as being benevolent.

A third dimension often reported by scholars that is also ethical is honesty, or the integrity of the trusted. Honesty refers to the extent to which the other is perceived to tell the truth and keep commitments. Benevolence and honesty are of a different nature than competence, as they reflect ethical traits rather than some kind of capability. Benevolence reflects the trustee's motives and is based on altruism; honesty reflects its integrity and willingness to tell the truth. In contrast, competence is a utilitarian dimension of trusting beliefs, as it refers to the functioning of government organizations themselves.

\section{How National Culture May Affect Transparency and Trust}

The debate on transparency and trust is often held in general terms. 'Transparency optimists' emphasize that transparency stimulates a 'culture of openness' within organizations, which is thought to have a positive effect on trust (Hood 2006, 217). Supposedly, transparency helps people to become more familiar with government, brings them closer together and creates understanding (Nye et al. 1997). Therefore, several authors argue that one cause for a lack of trust in government is that citizens are not often enough provided with factual documentation about government processes and performance (Bok 1997; Cook et al. 2010). On the other hand, 'transparency pessimists' question whether showing citizens the results of government policies will actually boost their trust (O’Neill 2002; Bannister and Connelly 2011). These pessimists argue that transparency may lead to politics of scandal and even 'delegitimization' 
of government. Critics also argue that transparency is overrated. For transparency to work, it needs users who are capable of processing it (Heald 2006). The latter is a fundamental problem of government transparency. If these users (be it citizens, journalists or other intermediaries) are interested at all, the information disclosed by governments is mostly too complex to digest, even for experts. There are limits to knowing, limits to the people's ability to process information (Etzioni 2010). Furthermore, checking the sources and who modified or added what information is difficult if not impossible, especially when disclosed on the Internet (Im et al. 2012). As a result, critics argue, online misinformation only leads to more uncertainty and less trust (O’Neill 2002). ${ }^{2}$

Recently, some empirical studies have been carried out (e.g. Tolbert and Mossberger 2006; Cook et al. 2010; De Fine Licht 2011; Morgeson et al. 2011, Porumbescu 2013), but these studies do not take into account country specific contexts that influence the relation between transparency and trust in government organizations. The next step in enhancing our understanding of the effects of transparency is to look at how it is affected by national culture.

There are many different perspectives on what a culture is, and consequently many definitions exist. In 1952, Kroeber and Kluckhohn conducted a critical review and found more than 160 different definitions of the term culture. Many other definitions have been developed since then. Kluckhohn himself developed an influential definition: 'By culture we mean all those historically created designs for living, explicit and implicit, rational, irrational, and nonrational, which exist at any given time as potential guides for the behavior of men.' Building on this perception of culture, Hofstede defines culture as 'the collective programming of the mind which distinguishes the members of one category of people from another.' (Hofstede, 2001, 9). These definitions view culture as an objective and collective 
phenomenon. A radically different view on culture is proposed by Clifford Geertz. Geertz, who has championed symbolic anthropology, focuses on the role of symbols in society. These symbols, which guide people's actions and serve to construct a shared culture, can therefore be understood as 'a system of inherited conceptions expressed in symbolic forms by means of which men communicate, perpetuate, and develop their knowledge about and attitudes toward life.' (Geertz, 1973, 89). Hence, according to Geertz' approach one needs to study symbols and the meanings given to them in order to understand culture. Culture helps people make meaning of society and the world around them. According to Geerts, in order to understand culture, we should study these processes of people construct meaning and the role of symbols in this process.

In this study, the influence of national cultures on transparency is compared. For this purpose we need a framework that allows for international comparison. Between 1967 and 1973 Geert Hofstede has carried out extensive research on the dimensions that constitute national culture, by comparing cultural values of people from over seventy countries (Hofstede, 2001). Five major dimensions of national culture are distinguished: power distance, uncertainty avoidance, individualism versus collectivism, masculinity versus femininity, and long-term versus short-term orientation. These dimensions cover how people cope with inequality, how people cope with uncertainty, the degree to which individuals are integrated into groups, and how roles between genders are expected to be divided. The fifth dimension was added later (Bond 1991) and is closely related to the teachings of Confucius. It can be thought of as whether a society is oriented towards the future from a long-term perspective, or if it has a short-term point of view.

The dimensions listed above provide a useful and well-established framework for comparing cultures. Therefore the work of Hofstede has been very influential. Nevertheless it suffers 
from two major limitations. First, the surveys he used were administered to employees of an international company (IBM). Secondly, only countries where IBM was established were included. As a consequence, the countries included in this study are mostly 'first world' countries.

In addition to these limitations, the work of Hofstede has been criticized for several other reasons. First, his work is criticized for assuming cultural homogeneity, whereas countries are made up various communities that can have cultures of their own (DiMaggio 1997). We indeed acknowledge that within a country, many subcultures exist and that even within these cultures individual ways of thinking may differ. However, the idea of national culture as a homogenous phenomenon, does not mean that it is deterministic in the sense that it predicts behavior of individuals, but it does by and large influence mental schemes and modes of thinking of an individual. In addition, both the Netherlands and South Korea are relatively homogenous cultures, and that means that although differences within countries exist, the value dimensions are still likely to be applicable to the overall population. A second major criticism is that Hofstede's work is outdated and not useable in a rapidly changing and globalizing world. Hofstede countered this by saying that national cultures are based on centuries of indoctrination and that recent replications support this (Jones, 2007). Hence national mental modes of thinking only change slowly and gradually, which means the results of Hofstede are still relevant. Third, more fundamentally the way culture is perceived by Hofstede is criticized. According to Hofstede's approach, cultures are general, objective and measureable entities, whereas, for example Geertz (1973) argues that cultures consist of symbols that help people make meaning and understand the world of the world around them. Culture, then, cannot not be analyzed as something objective or general, because symbols are given meaning by individuals in a subjective fashion, which suggests that cultures are not a 'collective programming of the mind', but instead is local and individual. 
Although these criticisms should be taken into account, Hofstede's work is, at present, the only international framework on cultural values that is supported by elaborate empirical research. As a result, this is by far the most cited and used work by scholars that are involved in cross-cultural research. Therefore, we will use Hofstede's dimensions of culture as a framework to compare the Netherlands and South Korea.

This study selected two of Hofstede's five dimensions (power distance and long-term versus short-term orientation) as we consider these dimensions to be most relevant to the purposes of this research; we explain why in the paragraph below. That said, future research, building upon the findings of this research may broaden the analysis to incorporate additional dimensions, either related to Hofstede's five cultural dimensions, or others in order to add greater depth to understanding how the effects of transparency may differ according to national context.

The dimension of power distance concerns the extent to which power inequalities in society are accepted and seen as normal. In contexts of high power distance, relations between leaders and citizens can be viewed as paternalistic in the sense that citizens are said to perceive themselves as largely dependent upon (and by extension vulnerable to) their government (Shin and Park 2003). Given perceptions of a dependency of citizens upon their government, and their subsequent vulnerability to the actions of their government, citizens' in high power distance contexts may be particularly sensitive to information that construes their government as anything other than omniscient and all powerful (cf. Grimmelikhuijsen 2012). Based upon such logic, we expect people in societies with high power distance values are more likely to respond negatively to transparency.

The second relevant dimension is the orientation of a culture, which could be longterm or short-term. Long-term cultures view the world in a predictable manner and presume 
things will develop in a predictable manner. In such societies government organizations tend to focus on the long-term, instead of centering attention at results in the here and now. This is related to government transparency as the goal of transparency policies and reforms are often focused on accountability on the short-term. For example, transparency shows whether goals and promises are fulfilled and are decisions made in a prudent manner. Long-term oriented societies tend to believe that good and evil, and "truth" depend on circumstances, whereas short-term oriented cultures generally view truth, good and evil in more of an absolute sense. Transparency is based on the very idea of revealing truth, a certain good or evil being is being revealed to the public: the philosophy behind transparency is that it shines 'a bright light' on how government works, and that 'sunshine' should be introduced into legislation (Etzioni 2010). As such, government transparency is expected to fit best with cultures that possess a short-term orientation. Hence, people in long-term oriented cultures will tend to view transparency more negatively, which will cause relatively negative effects of transparency on trust in government.

\section{Cross-national Comparison: the Netherlands and South Korea}

This paper combines a cross-national comparison with experiments and will as such test if there are interrelations between transparency and cultural settings. Comparative crossnational research is suitable to test macro-hypotheses and to test validated explanations in other cultural settings (Lijphart 1971, 685). Individuals are the units of analysis instead of the national structures itself, yet the effect of transparency on individuals is tested in a different cultural setting. Table 1 provides an overview of relevant country-level variables.

[Table 1 here] 
Table 1 shows that both countries are comparable on economic and political variables: they are both wealthy, advanced democratic societies. It should be noted that democracy in South Korea is still very young, with its transition occurring in the late 1980s. By contrast, the Dutch transition to democracy started in the mid-nineteenth century. In addition, South Korea and the Netherlands have sophisticated e-government systems. This means that the technological backbone of computer mediated transparency - information databases, online disclosure - in both countries is well developed which is relevant for their level of comparability. However, it should be noted that there are also important differences in the institutional arrangements between both countries. For example, the state structure in the Netherlands is characterized as a decentralized unitary state, whereas the South Korean state is in practice much more centralized (Im, Porumbescu, and Lee 2013). Further, the Dutch political system is a fragmented multi-party system. In contrast, South Korea's political system is more oriented toward a two-party system. While there is more to say about the institutional differences between these two countries, as this article primarily focuses on the cultural differences, we do not discuss institutional differences in greater detail than is done here.

Table 1 makes clear that both countries differ a great deal on the three relevant dimensions of national culture. It should be noted that scores on Hofstede's cultural dimensions only derive their meaning from comparison; a value of ' 60 ' on power distance is only meaningful relative to other values. As Table 1 points out there are clear cultural deviations between the Netherlands and South Korea. The Netherlands has a lower power distance, low uncertainty avoidance, and a short-term orientation, as compared to South Korea. 
The low score on power distance means that in general citizens in the Netherlands value being independent and having equal rights. Power in organizations is decentralized, control is disliked and communication is direct and participative. On the other hand, the high power distance score of South Korea indicates that people are accepting of a hierarchical order in which everybody has a place and where positions of authority need no further justification. Subordinates expect to be told what to do and authority is expected to be a benevolent autocracy.

The Netherlands is considered to be a short term oriented culture. Hence the Dutch tend to focus on the here and now and place an emphasis upon achieving quick results. Western societies are typically found at the short-term end of this dimension. In contrast, Asian countries are often considered long term oriented cultures, with South Korea being no exception. People are oriented toward the long term, and organizations have a tendency to focus on the durability of organizations and not on short term shareholder profit.

In section 3 we hypothesized that citizens in high power distance and long-term orientated cultures are expected to react more negatively government transparency since such initiatives are less compatible with their dominant values and beliefs. This means that transparency in South Korea is expected to have either a less positive or a stronger negative effect as compared to the Netherlands.

Bringing this all together, we propose the following hypotheses:

H1: Transparency will have a stronger negative/less positive effect on trust in government in national cultures with high power distance. 
H2: Transparency will have a stronger negative/less positive effect on trust in government in national cultures with a high long-term orientation.

\section{Method}

\subsection{Participants}

Three experiments were carried out in each country. The sample used here consists only of students, 381 in the Netherlands and 279 in South Korea. The background variables of both samples are shown in Table 2.

[Table 2 here]

It should be noted that the sample is not representative for the population of neither the Netherlands nor South Korea: people are relatively highly educated and the majority is oriented towards left wing and liberal political parties. ${ }^{3}$ The sample is probably relatively knowledgeable about the policy topic under scrutiny and more trusting towards government in general. That said, in this paper we are not interested in statistical generalization to the whole population as such, yet to generalizing the theoretical relation between transparency and trust.

Variables such as political preference might affect trust in government, and unequal distribution of these background variables potentially threatens the internal validity of the results. The most important background variables that might affect trust in government are 
considered to be gender, age, education, and political preference (e.g. King 1997; Putnam 2000). One of the variables (education) is constant since we only selected students as participants. The samples are comparable with regard to their average age and political selfidentification, yet differ on the male/female ratio. Although this might not necessarily alter the effect of transparency, this variable is controlled for in the main analysis.

\subsection{Operationalizing Transparency and Perceived Trustworthiness}

Transparency. Each experiment had a different operationalization of transparency. These operationalizations will be briefly described below. In each experiment there was a control group that received no information.

- Decision-making transparency focused on completeness of information: an experimental group received complete information about the decision-making process.

- Policy transparency focused on the 'coloring' of information: an experimental group received policy information that was 'balanced' (showed positive and negative sides of policy measures).

- Policy outcome transparency focused on both the timeliness and comprehensibility of information about certain policy outcomes. Two experimental groups received information that was easy to comprehend and timely.

The transparency operationalizations are summarized in Table 3 below.

[Table 3 here] 
The three combinations shown in bold were investigated in this study. This means that three combinations have been tested in separate experiments.

Perceived Trustworthiness. Perceived trustworthiness was measured after the experiment by means of a questionnaire. Participants were asked specifically about the perceived benevolence, competence, and honesty of the government organization with regard to the topic. All dimensions were measured on a five-point scale and are derived following a trust scale validated by McKnight et al. (2002), and then tested and adapted to the public sector context. Survey items for variables mentioned in this section can be found in the appendix.

\subsection{Experimental Setting and Procedure}

The Dutch experimental setting addressed air pollution at the local level. Air pollution is a widespread problem in numerous cities in a great deal of countries worldwide (see for example the OECD Environmental Outlook to 2030). This paper examines the case of air pollution in local governments because of its importance in public policy. Further, information disclosure is an important issue in air pollution policy. In the Netherlands, government organizations must comply with the Dutch Freedom of Information Act (FOIA) and the Aarhus Treaty. The Aarhus Treaty was adopted on 25 June 1998 and entered into force on 30 October 2001 by the United Nations Economic Commission for Europe (UNECE) and encourages proactive (electronic) environmental communication of governments toward the public. The Dutch FOIA prescribes that environmental information should be disclosed more extensively than other information. All ratifying countries commit 
to implement easier (electronic) means of public access to environmental information. Hence, air pollution is considered to be a highly relevant case for studying transparency.

The South Korean experimental setting addressed identity theft prevention at the national level. In South Korea, identity theft is a widespread problem throughout the country and can be seen as a much more topical issue when compared to air pollution in terms of the attention it receives from policy makers and citizens. To explain, in South Korea, identity theft has become a major issue, with more than one million cases being officially recorded over the course of the past decade (Statistics Korea 2012). Identity thefts have tended to be most pronounced in the Seoul area (Seoul Metropolitan Police Agency 2011). Due to the frequency of identity theft in South Korea, this issue has become a prominent topic among citizens as well as in the South Korean legislature, which in 2011 passed the 2011 Privacy Act. Additionally, we focus upon the central level of government of the Korean government as opposed to the local level of government as in the Netherlands. Here, the reason also relates to salience; two points are used to illustrate. First, in South Korea, positions at the local levels of government were all appointed by the central government; until recently there were no elections for positions such as mayor. This means that there was little discrepancy between the policies pursued at the local level of government and the central government. Second, South Korea has a long history of government being highly centralized, dating back all the way to the $15^{\text {th }}$ century, which has led Korean citizens to place particular emphasis upon the activities of the central government, as opposed to the activities of local governments. Given these traditions, Korean citizens can be viewed as placing greater emphasis upon the activities of the central government, with issues at the local level of government resonating less with Korean citizens. 
As the paragraphs above have explained, the policy topic and level of government used in this study's comparison differs between South Korea and the Netherlands. This difference in policy topics and levels of government is not arbitrary but rather intends to strengthen the comparison that is carried out in this study. The reason for this relates to the salience of the issue and level of government to citizens in the Netherlands and South Korea; is the issue and level of government one that citizens are interested in or care about? This is important to consider because, conceivably transparency is only likely to impact trust in government - as suggested by previous research - in the event that the information afforded to citizens via transparency policies pertains to an issue about government they feel is important (Cook et al. 2010). A difficulty in comparing the effects of transparency policies on levels of trust in government between two nations is ensuring that the policies and levels of government addressed are ones that citizens are interested in; surely traditions of government and the salience of policies varies according to national context (Pollitt and Bouckaert 2004, Painter and Peters 2010). This study has emphasized choosing policies and levels of government that resonate with the citizens, as opposed to ensuring that policies and levels of government match as salience of policy issues and citizens' interest in levels of government is likely to differ according to national context (Welch and Wong 1998).

General Experimental Procedure. The procedure consisted of three elements: (1) instructions in what was involved in the experiment with some general questions, (2) presenting the stimuli, and (3) a post-test questionnaire. Each of these elements will be explained.

1. At the start, participants were shown questions about prior visits of government websites and prior knowledge about the topic. It should be noted that participants were randomly assigned to the different websites. A click on a link led them to one of 
the two websites in the experiment. Before clicking on the link, the questionnaire told participants to read the website and to follow the instructions on the website.

2. Each experiment consisted of multiple website pages. All three experiments first presented participants with a general explanation about decision-making/policy/policy outcome in question. People were then instructed to click on to the next page which provided respondents with specific information. For example, in the decision-making transparency experiment people were shown actual information about decisionmaking regarding either environmental policy (the Netherlands) or identity theft policy (South Korea). In the case of the policy transparency experiment participants were shown information about policy measures. Finally, for the policy outcome transparency experiment results of each policy was presented to participants. The control group only completed a questionnaire and hence did not look at a website.

3. At the end, they were asked to close the window of their browser and to complete a post-experimental questionnaire. The participants in the control group were directed to the questionnaire directly, without visiting the municipal website. It should be noted that culture may affect survey response. Shulruf, Hattie and Dixon (2011) found that individualist cultures tend to use more extreme responses, whereas collectivist cultures tend to use more neutral and social desirable responses. Hence the Korean participants are expected to be middle responders. However, in this study there is no reason to belief that such a bias occurred since the Korean results were much less grouped around the middle score of 3, than the Dutch results (see table 6, 7, and 8 for more details).

\subsection{Analysis}


The analysis of results consisted of three steps. First a multivariate analysis of covariance was carried out. A MANCOVA was considered to be suitable because of the categorical nature of independent variables, and the use of multiple dependent variables (i.e. perceived competence, benevolence and honesty), which have a continuous nature. Further, the use of MANCOVA implies the existence of covariates. Covariates used were: gender, political preference and age. These were used to control for confounding influences of background variables that are known to have a potential effect on trust in government. "Educational level" was not included as a covariate as all participants were students and thus had equal education. The overall multivariate effect indicates whether some significant difference occurs in the data without specifying the effect. If multivariate significance can be determined, the second step tests on which specific dimension this effect occurs. To do so, univariate analyses of covariance (ANCOVA) were carried out, with the same covariates as in the prior MANCOVA. Third, the means of the control and experimental groups were compared and tested for significant mean differences to obtain further details about the effect of transparency. Significance levels were set at $\mathrm{p}<0.05$.

\section{Results ${ }^{4}$}

The results of each experiment will be discussed separately.

Decision-making Transparency. The analysis shows that significant multivariate differences are detected between the complete information group and the control group, in South Korea $\left(\mathrm{F}(1,52)=16.58, p<.001\right.$ eta $^{2}=.509$. In the Netherlands no significant results were found $\left(\mathrm{F}(1,50)=0.81, p=.494\right.$ eta $\left.^{2}=0.050\right)$. This means that in the South Korean experiment decision-making transparency has a significant effect on perceived trustworthiness. In the Netherlands, however, no significant effect was found. This does not tell us anything about the exact group differences. In order to shed more light on this we now 
turn to carrying out pair-wise group comparisons. The results are displayed in Table 4. If means have a superscript in common within rows, no statistical difference was found between those groups.

[Table 4 here]

As table 4 shows, in the Netherlands no significant differences are found when comparing no transparency (control) versus full levels of information. The South Korean results show another pattern and are much more clear-cut: people who were shown complete decisionmaking information were much more negative about the perceived competence of the government organization (-0.93), which is indicated by the different superscripts ' $a$ ' and ' $b$ ' The perceptions of the other two dimensions remained equal.

Policy Transparency. The analysis shows that significant multivariate differences are detected between the balanced information group and the control group only in the South Korean case $(\mathrm{F}(1,44)=3.27, p<0.05)$, thus proving an effect of policy transparency only in this experiment. The Dutch experiment did not show evidence of a significant effect. Further analysis of the Korean experiment shows that policy transparency affects only perceived competence $\left(\mathrm{F}(1,44)=4.66, p<.05\right.$, eta $\left.^{2}=.102\right)$.

[Table 5] 
Again the trust in the specific government organization is lower in South Korea than in the Netherlands. Also for policy transparency the overall patterns are similar. Nevertheless, the only significant difference found regards perceived competence: if people receive more balanced information (in the South Korean case) this leads to more negative evaluation of competence. The same pattern applies to the Dutch case, however, the effect is not strong enough to render the relationship statistically significant. Further, the means of benevolence and honesty in both countries are slightly higher in the group that received balanced information. This indicates that the experimental stimulus is perceived in a similar way in both countries. Also it indicates that they are measuring the same thing in both countries. Nevertheless, the main point is that although the patterns amongst countries are comparable, the negative effect of policy transparency on perceived competence in South Korea is rather large (-0.4), whereas this is absent in the Netherlands.

Policy Outcome Transparency. The multivariate effect of policy outcome transparency was significant in the case of South Korea $\left(\mathrm{F}(1,46)=4.99, p<.000\right.$, eta $^{2}=.254$. The case of the Netherlands was also significant $\left(\mathrm{F}(1,502)=1.57, p=.158\right.$, eta $\left.^{2}=.039\right)$. In the policy outcome experiment both the effect of positive and negative outcomes were taken into account. A subsequent analysis of results shows more specific effects of transparency, and whether it matters to provide positive or negative policy outcome information to the public.

[Table 6 here] 
In the Dutch case policy outcome transparency only has a small effect. Table 8 shows that negative policy outcomes are related with lower levels of perceived competence, when contrasted with positive outcomes, indicated by the different superscripts ' $a$ ' and ' $b$ '. However, there is no statistical difference between the negative outcome group and the control group. The double superscript for the control group in Table 8 for the Netherlands signals that that no significant differences were found between the control group and the two experimental groups. So, the negative policy outcome has some negative effect on perceived competence but this is effect is ambiguous.

The Korean participants responded much more clearly: a large negative effect on perceived competence was found (-1.06). On the other hand, a positive policy outcome transparency did not have a positive effect on perceived competence. Interestingly, perceived benevolence and honesty were judged more positively when positive policy outcomes were made transparent. Because of the low $\mathrm{N}$ in the Korean case these differences are not significant at the set confidence interval of 5 percent.

\section{Conclusion and Discussion}

Over the course of the past few decades, government transparency has garnered a great deal of political and academic attention (e.g. Roberts 2006; Hood and Heald 2006; Meijer 2009; Piotrowski 2007; Bannister and Connelly 2011; Grimmelikhuijsen 2012). What this study has examined in particular is the way in which transparency may impact citizens' attitudes toward their government and how this may vary amongst national cultures. The results of this study turned back mixed results, which lead us to reject both hypotheses. Nevertheless, these results have important implications for the debate on transparency. 
With respect to the dimension of competence, the results of all three experiments suggest that the effects of transparency differed in South Korea from those in the Netherlands. In particular, all three experiments suggest that transparency significantly contributes toward reduced perceptions of government competence among South Korean citizens. In the case of the Netherlands transparency only returned significant effects - also negative - with respect to negative policy outcomes upon citizens' perceptions of government competence. While both contexts returned negative relationships between the trust dimension of competence and transparency, South Korean citizens consistently exhibited more extreme responses to the information afforded to them, when compared to their counterparts in the Netherlands. These findings suggest the impact of transparency on citizens' trust in government in particular is likely to be differentiated according to a country's cultural context.

Additionally, it is interesting to note that, while transparency also appeared to influence citizens' perceptions of the honesty and benevolence dimensions of trust, the effects were not significant; neither in the Netherlands, nor in South Korea. This is interesting because presumably as the government opens its doors to citizens, at the very least one would expect citizens to perceive their government as more honest, yet such effects were rather subdued.

An important implication of these results is that, although some similar patterns were detected, the effect of government transparency appears to be partly culturally dependent. Apparently, in terms of generating trust, transparency fits less in cultures that possess higher power distances and are culturally more oriented toward the long term, such as South Korea. Transparency thus seems to fit better with cultures oriented toward the short-term and have low power distance. Short-term orientations emphasize the need for results in the here and now and perceive 'truth' as an absolute thing. Furthermore, low power distance cultures 
generally do not accept large distances in any given power structure, which explains why transparency - essentially a power reducing mechanism, as it is a means to render accountability of the ones in power - fits better in the Netherlands than in South Korea.

An overarching explanation for our findings is that, in such cultural contexts, citizens interpret information afforded to them via transparency policies as evidence that their government is not as omniscient as they had previously thought. Given that, in contexts of high power distance, citizens view their wellbeing as contingent upon the actions of their government, citizens may be particularly sensitive to information afforded to them via transparency policies that construes their government in a less competent light. Alternatively, in contexts of lower power distance, like the Netherlands, where citizens view their wellbeing as being less dependent upon the actions of their government, citizens may not be particularly responsive to information afforded to them via transparency policies that construe their government as being less than omniscient. Of course, the explanations provided here are not intended serve as a definitive explanations for the findings of this study, but rather serve to highlight the weakness of attempts to blindly generalize the overly positive and universal claims that are commonly made about government transparency worldwide.

Our understanding of how the consequences of transparency needs to be furthered by carrying out similar studies in different countries. This could shed further light on how separate cultural dimensions affect transparency and trust. This study has focused in particular upon comparing outcomes of transparency policy in the Netherlands and South Korea, using Hofstede's cultural dimensions of power distance and long term orientation. However, future research may address other dimensions of culture may also be used to explain the findings of this study. For example, Hofstede's dimension of uncertainty avoidance is very much related to the dimensions of power distance and long term orientation. 
In addition, future research may explore alternative explanations, as national cultural dimensions as proposed by Hofstede (2001) may not be the only explanation. As Lijphart (1971) highlighted, comparative cross-national research is suitable to test macro-hypotheses and to test validated explanations in other cultural settings. However, the variables that differ amongst countries are potentially numerous. For example, an alternative explanation may be that the Dutch people are much more used to a relatively open government, free press and have a long democratic standing. They might therefore not only be better informed, but might also be more used to prior critical coverage of government activities. Hence, in contexts where citizens are likely to be better informed of the activities of their government, their opinions are likely to be less sensitive to new information that would be provided to them via transparency policies implemented by government. Conversely, in contexts that lack long established track records with respect to open government, citizens' may be more sensitive to the information that transparency policies afford them.

The second major implication that can be drawn from the findings of this research is that the effects of transparency on citizens' trust in government appear more pronounced with respect to their negative impact on citizens' trust in government than they do with respect to their positive impact. Moreover, the findings of this research suggest that transparency may do little to improve citizens' opinion of government, at least in the short term. To this end, it is possible to view these findings as an extension of previous work done by Kampen and colleagues (2006), who found that citizens' negative experiences with government has a much more pronounced effect upon their levels of trust in government than positive experiences, leading the authors to the conclusion that "trust comes on foot and goes away on horseback" $(2006,389)$. Thus, while citizens in contexts that possess a longer history of open government may be less sensitive to new information afforded to them by transparency 
policies, this lack of sensitivity appears to disappear when specifically negative information is introduced, as suggested by the experiment related to policy outcomes in the case of the Netherlands.

Finally, this study is not without its limitations. Most formidable of the limitations in this study is that the sample used for analysis consisted of students from top ranked universities in the Netherlands and South Korea. Every empirical piece of research faces a trade off in terms of choosing the methodology it adopts (Shadish, Cook, and Campbell 2002). This study adopted an experimental methodology as this methodology is generally viewed as being the best at assessing causal relationships, as opposed to assessing associations, which larger $n$ empirical work often does. However, the drawback associated with experimental methodologies is that, often times, it is prohibitively expensive to carry out experiments on the same scale that other forms of empirical analysis are, such as those based on surveys. As such, the results of this study should be interpreted with caution. What issues could be raised against this bias? Prior studies have shown that the most important background variables that might affect trust in government are sex, political preference, education and age (e.g. Cook and Gronke, 2005). Especially education and age might be problematic since students are relatively highly educated and young. Age is thought to have a negative effect on trust in government, whereas the level of education has a positive effect.

That said, it is also important to consider some benefits associated with using samples of students for experimental research. As a methodology, experiments are useful in addressing causal relationships by controlling for confounding effects. However, the ability to control for confounding effects is only as good as the samples are homogeneous. To this end, making use of samples of students allows research to control for any sources of endogeneity (such as 
omitted variable bias) that may be present in the relationship between citizens' trust in government and transparency (Wooldridge 2004). For example, previous research has suggested that the effects of transparency upon trust may be differentiated according to citizens' motivation in acquiring new information, cognitive capacity, and personal traits (Cook et al. 2010). Presumably, by comparing samples of students from top universities in the Netherlands and South Korea, a broader spectrum of confounding effects is likely to be controlled for, when compared to comparing samples of the population at large, which is likely to differ a great deal with respect to citizens' motivation to acquire government information, cognitive capacity, and personal traits.

Even when these limitations are considered, there are some important lessons for government organizations that arise from these results. The main lesson is that public officials and political leaders should expect no wonders from transparency. It is no magic and universal cure for trust in government. The differences in the magnitude of transparency's effect in both countries suggest that national cultural values play a significant role in how people perceive and appreciate government transparency. This means that in designing transparency policy with an aim of rendering higher levels of citizen trust officials need to take into account national culture. This may even count for subcultures within countries or between regions and needs further investigation.

\section{Notes:}

1. Typically 'information' is distinguished from 'data'. Information has meaning for the recipient, whereas data are the bare 'facts and figures'. In this article we only focus on 'information'.

2. We acknowledge that many other factors affect trust in government, for a more comprehensive discussion on this is referred to the works of for example Nye et al., 1997 and Putnam, 2002. 
3. It should be noted that "left wing" means different things in different political systems. According to the online database of the Manifesto Research Project (Volkens et al., 2012) South Korean political parties are relatively left wing compared to Dutch political parties. In South Korea, Hannara Dang is considered to be the conservative and right-wing where as Minju Dang is generally considered to be the left-wing party. This is how left-wing and right-wing participants were gauged. In the Netherlands participants with a voting preference for the Green Left (Groen Links), Labour (PvdA), Animal Party (PvdD), Democrats (D66) and the Socialist Party (SP) were gauged left-wing.

4. It should be noted that the results of the Dutch experiments have been published in different venues. For this article only students were selected from the original database to ensure comparability with the South Korean experiments.

\section{References}

Bannister, Frank, and Connolly, Regina. 2011. "The Trouble with Transparency: A Critical Review of Openness in e-Government." Policy and Internet 3(1), Article 8.

Birkinshaw, Patrick .J. 2006. “Transparency as a Human Right.” In Transparency: The key to better governance?, edited by Christopher Hood and David Heald, 47-58. Oxford: Oxford University Press.

Bok, Derek. 1997. "Measuring the Performance of Government." In Why People Don't Trust Government, edited J. Nye, P. Zelikow, and D. King, 55-75. Cambridge, MA: Harvard University Press.

Bond, Michael H. 1991. Beyond the Chinese face: Insights from psychology. Hong Kong: Oxford University Press. 
Bouckaert, Geert, and van de Walle, Steven. (2003) 'Comparing Measures of Citizen Trust and User Satisfaction as Indicators of "Good Governance": Difficulties in Linking Trust and Satisfaction Indicators'. International Review of Administrative Sciences 69(2): 329-43.

Cook, Timothy E., and Gronke, Paul. 2005. "The skeptical American: revisiting the meanings of trust in government and confidence in institutions." Journal of Politics 67(3): 784-803.

Cook, Fay .L., Jacobs, Lawrence R., and Dukhong. Kim. 2010. “Trusting What You Know: Information, Knowledge, and Confidence in Social Security." The Journal of Politics 72(2): $397-412$.

Curtin, Deirdre, and Albert J. Meijer. 2006. "Does Transparency Strengthen Legitimacy?" Information Polity 11(2): 109-123.

Davis, Richard. 1999. The Web of Politics: The Internet's Impact on the American Political System. New York: Oxford University Press.

Dawes, Sharon S. 2010. “Stewardship and usefulness: Policy principles for informationbased transparency." Government Information Quarterly 27(4): 377-383.

De Fine Licht, Jenny. 2011. "Do We Really Want to Know? The Potentially Negative Effect of Transparency in Decision Making on Perceived Legitimacy." Scandinavian Political Studies 34(3): 183-201.

DiMaggio, Paul. 1997. “Culture and Cognition.” Annual Review of Sociology 23(1): 263-287. 
Drew, Christina H., and Timothy L. Nyerges. 2004. “Transparency of Environmental Decision Making: A Case Study of Soil Cleanup inside the Hanford 100 Area.” Journal of Risk Research 77(1): 33-71.

Etzioni, Amital. 2010. "Is transparency the best disinfectant?" The Journal of Political Philosophy 18(4): 389-404.

Florini, Ann. 1998. "The end of secrecy." Foreign Policy 111, 50-63.

Gerring, John, and Strom C. Thacker. 2004. "Political Institutions and Corruption: The Role of. Unitarism and Parliamentarism.” British Journal of Political Science 34: 295-330.

Grimmelikhuijsen, Stephan G. 2012. "A good man but a bad wizard. About the limits and future of transparency of democratic governments." Information Polity, forthcoming.

Grimmelikhuijsen, Stephan G., and Albert J. Meijer. 2012. "The Effects of Transparency on the Perceived Trustworthiness of a Government Organization: Evidence from an Online Experiment." Journal of Public Administration Research and Theory, advance access.

Grimmelikhuijsen, Stephan G., and Eric W. Welch. 2012. "Developing and Testing a Theoretical Framework for Computer-Mediated Transparency of Local Governments.” Public Administration Review 72(4): 562-571. 
Heald, David. 2006. "Varieties of Transparency." In Transparency: The key to better governance?, edited by Christopher Hood and David Heald, 25-43. Oxford: Oxford University Press.

Hetherington, Marc .J. 1998. "The Political Relevance of Political Trust.” The American Political Science Review 92(4): 791-808.

Hofstede, Geert. 2001. Culture's Consequences: Comparing Values, Behaviors, Institutions, and Organizations Across Nations. Second Edition, Thousand Oaks CA: Sage Publications. Hood, Christopher. 2006. "Beyond Exchanging First Principles? Some Closing Comments." In Transparency: The key to better governance?, edited by Christopher Hood and David Heald, 211-226. Oxford: Oxford University Press.

Im, Tobin, Cho, Wonhyuk, Porumbescu, Greg, and Jungho Park. 2012. Internet, Trust in Government, and Citizen Compliance. Journal of Public Administration Research and Theory, advance access.

Im, Tobin, Porumbescu, Greg, Lee, Hyunkuk. 2013. ICT as a buffer to change? A case study of the Seoul Metropolitan Government's Dasan Call Center. Public Performance and Mangement Review, 36(3): 436-456.

Jones, Michael L. "Hofstede - Culturally questionable?" Oxford Business and Economics Conference. Oxford, UK, 24-26 June, 2007. 
Kampen, Jarl, Van de Walle, Steven, and Bouckaert, Geert. 2006. Assessing the Relation Between Satisfaction with Public Service Delivery and Trust in Government: The Impact of Predisposition of Citizens Toward Government on the Evaluations of it Performance. Public Performance and Management Review, 29(4): 387-404.

Kim, Seok-Eun. 2005. "The Role of Trust in the Modern Administrative State: An Integrative Model.” Administration and Society 37(5): 611-635.

King, David C. 1997. “The polarization of American parties and mistrust of government.” In Why people don't trust government, edited by J. Nye, P. Zelikow, and D.C. King, 155-178. Cambridge, MA: Harvard University Press.

Kramer, Roderick and Roy J. Lewicki. 2010. Repairing and Enhancing Trust: Approaches to Reducing Organizational Trust Deficits. The Academy of Management Annals, 4(1): 245-277.

Larsson, Torbjörn. 1998. “How Open Can Government Be? The Swedish Experience.” In Openness and Transparency in the European Union, edited by V. Deckmyn, and Thomson, 39-51. Maastricht: European Institute of Public Administration.

Levi, Margaret and Laura Stoker. 2000. "Political Trust and Trustworthiness." Annual Review of Political Science 3: 375-407.

Lijphart, Arend. 1971. "Politics and the comparative method." The American Political Science Review 65(3): 682-693 
Mahler, Julianne and Priscilla M. Regan. 2007. "Crafting the Message: Controlling Content on Agency Web Sites.” Government Information Quarterly 24: 505-521.

McKnight, D. Harrisson, Choudhury, Vicek, and and Charles Kacmar. 2002. "Developing and validating trust measures for e-commerce: An integrative typology." Information Systems Research 13(3): 334-359.

Meijer, Albert J. 2009. Understanding Computer-mediated Transparency. International Review of Administrative Sciences 75(2): 255-269.

Moon, M. Jae, and Norris, Donald F. 2005. "Does Managerial Orientation Matter? The Adoption of Reinventing Government and E-Government at the Municipal Level.” Information Systems Journal 15(1): 43-60.

Morgeson III, Forest V., VanAmburg, David and Sunil Mithas. 2011. "Misplaced Trust? Exploring the Structure of the E-Government-Citizen Trust Relationship." Journal of Public Administration Research and Theory 21(2): 257-283.

Nye, Joseph S., Zelikow, Phillip D., and D.C. King. 1997. Why people don't trust government. Cambridge: Harvard University Press.

O’Neill, Onora. 2002. A question of trust: The BBC Reith lectures 2002. Cambridge: Cambridge University Press. 
Organisation for Economic Co-operation and Development (OECD). 2008. Key Environmental Indicators 2008. Paris: OECD.

Painter, M.A. and B. Guy Peters (Eds.). 2010. Tradition and Public Administration. Basingstoke: Macmillan.

Peters, Richard G., Covello, Vincent T. and David .B. McCallum. 1997. "The Determinants of Trust and Credibility in Environmental Risk Communication: An Empirical Study.” Risk Analysis 17(1): 43-54.

Piotrowski, Suzanne J. 2007. Governmental Transparency in the Path of Administrative Reform. SUNY press: Albany, NY.

Pollitt, Christopher and Geert Bouckaert. 2004. Public Management Reform. A Comparative Analysis. Oxford: Oxford University Press, second edition.

Porumbescu, Gregory. 2013. An assessment of the impact of citizens' use of e-government and online mass media on levels of trust in government. Doctoral dissertation. Seoul National University.

Putnam, Robert. 2000. Bowling Alone. The Collapse and Revival of American Community. New York: Simon and Schuster.

Roberts, Alasdair. 2006. Governmental adaptation to transparency rules. In C. Hood, and D. Heald (Eds.), Transparency: The key to better governance? (pp. 107-144). Oxford: Oxford University Press. 
Rousseau, Denise, Sitkin, Sim, Burt, Ronald and Colin Camerer. 1998. "Not so Different After All: A Cross-Discipline View of Trust." The Academy of Management Review 23(3): 393-404.

Seoul Metropolitan Police Agency 2011. Statistics and Public Security. Seoul Metropolitan Police Agency. Seoul, South Korea.

Shadish William R., Thomas D. Cook and Donald T. Campbell. 2002. Experimental and quasi-experimental design for generalized causal inference. Houghton Mifflin Company: Boston, New York.

Shin and Park 2003. Social Capital and Democratic Citizenship: The Case of South Korea. Asian Barometer Working Paper.

Shulruf, Boaz, John Hattie and Robyn Dixon. 2011. "Intertwinement of individualist and collectivist attributes and response sets." Journal of Social, Evolutionary, and Cultural Psychology 5(1): 51-65.

Statistics Korea 2012. Korean Statistical Information Service. Government of South Korea. Seoul, South Korea.

Tolbert, Caroline J., and Mossberger, Karen. 2006. “The Effects of E-Government on Trust and Confidence in Government." Public Administration Review 66(3), 354-369. 
Volkens, Andrea, Onawa Lacewell, Pola Lehmann, Sven Regel, Henrike Schultze and Annika Werner. 2012. The Manifesto Data Collection. Manifesto Project (MRG/CMP/MARPOR). Berlin: Wissenschaftszentrum Berlin für Sozialforschung (WZB)

Welch, Eric W., Charles C. Hinnant and M. Jae Moon. 2005. "Linking Citizen Satisfaction with E-Government and Trust in Government." Journal of Public Administration Research and Theory 15(3): 371-391.

Welch, Eric, and Wilson Wong. "Public administration in a global context: bridging the gaps of theory and practice between Western and Non-Western nations." Public Administration Review (1998): 40-49.

Wooldridge, Jeffrey, M. 2004. Introductory Econometrics: A Modern Approach. Mason, OH: South Western Cengage Learning.

Yamagishi, Toshio and Midori Yamagishi. 2010. Trust and Commitment in the United States and Japan. Motivation and Emotion, 18(2): 129-166.

Zucker, Lynne G. 1986. "Production of trust: Institutional sources of economics structures, 1840-1920.” In Research in organizational behavior, edited by B.M. Staw and L.L. Cummings, Vol. 8, 53-122. Greenwich, CT: JAI Press. 
Table 1 - Summary of comparison between the Netherlands and South Korea

\begin{tabular}{|l|c|c|}
\hline \multicolumn{1}{|c|}{ The Netherlands } & South Korea \\
\hline Industrialized society & Yes & Yes \\
\hline Democratic & Yes & Yes \\
\hline Economy & $\begin{array}{c}\text { Advanced } \\
\text { (GDP per capita in 2011 \$41,949) }\end{array}$ & $\begin{array}{c}\text { Advanced } \\
\text { (GDP per capita } \$ 31,753 \text { in 2011) }\end{array}$ \\
\hline $\begin{array}{l}\text { E-government } \\
\text { sophistication }\end{array}$ & $2^{\text {nd }}$ \\
\hline National Culture & UNPAN ranking & UNPAN ranking \\
\hline Power Distance & 38 & 60 \\
\hline Long-term Orientation & 44 & 75 \\
\hline
\end{tabular}

Criteria used by UNPAN to derive these rankings consist of three components; an online service component, a telecommunication infrastructure component, and a human capital component. For the survey, 190 nations were evaluated.

Scores for national culture are relative. A lower score suggests that a cultural dimension is less present in particular nation when compared to other nations examined. A higher score suggests that a cultural dimension is more pronounced in a particular nation when compared to the other nations examined. 
Table 2 - Overall sample of three experiments

\begin{tabular}{|l|c|c|}
\hline & $\begin{array}{c}\text { The Netherlands } \\
(\mathbf{N = 3 8 1})\end{array}$ & $\begin{array}{c}\text { South Korea } \\
(\mathbf{N = 2 7 9})\end{array}$ \\
\hline \% Male & $37.3 \%$ & $60 \%$ \\
\hline Average age $(\mathrm{sd})$ & $23.7(2.21)$ & $22.5(2.01)$ \\
\hline \% (moderate) liberal & $58.3 \%$ & $56.1 \%$ \\
\hline
\end{tabular}


Table 3 - summary of transparency operationalization

\begin{tabular}{|c|c|c|c|c|}
\hline \multirow{5}{*}{ 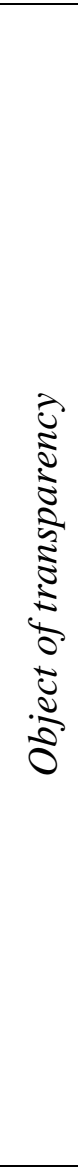 } & & \multicolumn{3}{|c|}{ Dimension of transparency } \\
\hline & & Completeness & Color & Usability \\
\hline & Decision-making & $\begin{array}{l}\text { Complete } \\
\text { information (e.g. } \\
\text { elaborations and } \\
\text { rationale behind } \\
\text { decisions) about } \\
\text { the decision- } \\
\text { making process } \\
\text { are available. }\end{array}$ & $\begin{array}{l}\text { Information is } \\
\text { reflecting all } \\
\text { values and } \\
\text { opinions in the } \\
\text { process. }\end{array}$ & $\begin{array}{l}\text { Decision-making } \\
\text { process made } \\
\text { insightful in a } \\
\text { timely and } \\
\text { understandable. } \\
\text { manner. }\end{array}$ \\
\hline & $\begin{array}{l}\text { Policy } \\
\text { information }\end{array}$ & $\begin{array}{l}\text { All relevant policy } \\
\text { plans and } \\
\text { measures are } \\
\text { available. }\end{array}$ & $\begin{array}{l}\text { Reflecting both } \\
\text { negative and } \\
\text { positive issues } \\
\text { about the policy. }\end{array}$ & $\begin{array}{l}\text { Policy plans and } \\
\text { measures are } \\
\text { made insightful } \\
\text { in a timely and } \\
\text { understandable } \\
\text { manner. }\end{array}$ \\
\hline & Policy outcome & $\begin{array}{l}\text { All qualitative and } \\
\text { quantitative data } \\
\text { about relevant } \\
\text { policy outcomes } \\
\text { are available. }\end{array}$ & $\begin{array}{l}\text { Effects are } \\
\text { determined } \\
\text { objectively, there } \\
\text { is room for } \\
\text { dissenting } \\
\text { opinions about } \\
\text { policy outcome. }\end{array}$ & $\begin{array}{l}\text { Policy outcomes } \\
\text { are made } \\
\text { insightful in a } \\
\text { timely and } \\
\text { understandable } \\
\text { manner. }\end{array}$ \\
\hline
\end{tabular}


Table 4-Group comparisons of perceived competence, benevolence and honesty for decision-making transparency

\begin{tabular}{|c|c|c|c|c|}
\hline & $\begin{array}{r}\text { The Netl } \\
(\mathrm{N}=\end{array}$ & $\begin{array}{l}\text { erlands } \\
\text { 53) }\end{array}$ & $\begin{array}{r}\text { Sout } \\
(1\end{array}$ & $\begin{array}{l}\text { Korea } \\
\text { 55) }\end{array}$ \\
\hline $\begin{array}{l}\text { Dependent } \\
\text { Variable }\end{array}$ & Control group & $\begin{array}{c}\text { Complete } \\
\text { information }\end{array}$ & $\begin{array}{l}\text { Control } \\
\text { group }\end{array}$ & $\begin{array}{c}\text { Complete } \\
\text { information }\end{array}$ \\
\hline $\begin{array}{l}\text { Perceived } \\
\text { Competence }\end{array}$ & $3.38(.09)^{\mathrm{a}}$ & $3.28(.09)^{\mathrm{a}}$ & $2.66(.13)^{\mathrm{a}}$ & $1.73(.10)^{b}$ \\
\hline $\begin{array}{l}\text { Perceived } \\
\text { Benevolence }\end{array}$ & $3.34(.09)^{\mathrm{a}}$ & $3.46(.09)^{\mathrm{a}}$ & $2.05(.12)^{\mathrm{a}}$ & $2.10(.10)^{\mathrm{a}}$ \\
\hline $\begin{array}{l}\text { Perceived } \\
\text { Honesty }\end{array}$ & $3.07(.10)^{\mathrm{a}}$ & $3.25(.10)^{\mathrm{a}}$ & $1.88(.12)^{\mathrm{a}}$ & $1.64(.10)^{\mathrm{a}}$ \\
\hline
\end{tabular}

Rows with unequal superscripts differ significantly at $p<0.05$. No multiple comparison correction since only one comparison per dimension was carried out. Means displayed, standard errors in parentheses. Covariates: age, sex $(1=$ male $)$, and political preference $(1=$ left-wing $)$. 
Table 5 - Group comparisons of perceived competence, benevolence and honesty for policy transparency

\begin{tabular}{|l|ll|lc|}
\hline & \multicolumn{2}{|c|}{$\begin{array}{c}\text { NL } \\
\text { (N=52) }\end{array}$} & \multicolumn{2}{c|}{$\begin{array}{c}\text { SK } \\
(\mathbf{N = 4 6 )}\end{array}$} \\
\hline $\begin{array}{l}\text { Dependent } \\
\text { Variable }\end{array}$ & Control group & $\begin{array}{l}\text { Balanced } \\
\text { information }\end{array}$ & $\begin{array}{l}\text { Control } \\
\text { group }\end{array}$ & $\begin{array}{l}\text { Balanced } \\
\text { information }\end{array}$ \\
\hline $\begin{array}{l}\text { Perceived } \\
\text { Competence }\end{array}$ & $3.22(.11)^{\mathrm{a}}$ & $3.02(.13)^{\mathrm{a}}$ & $2.37(.13)^{\mathrm{a}}$ & $1.97(.12)^{\mathrm{b}}$ \\
\hline $\begin{array}{l}\text { Perceived } \\
\text { Benevolence }\end{array}$ & $3.60(.10)^{\mathrm{a}}$ & $3.83(.12)^{\mathrm{a}}$ & $2.11(.11)^{\mathrm{a}}$ & $2.24(.10)^{\mathrm{a}}$ \\
\hline $\begin{array}{l}\text { Perceived } \\
\text { Honesty }\end{array}$ & $3.22(.11)^{\mathrm{a}}$ & $3.31(.13)^{\mathrm{a}}$ & $1.69(.10)^{\mathrm{a}}$ & $1.85(.10)^{\mathrm{a}}$ \\
\hline
\end{tabular}

Rows with unequal superscripts differ significantly at $p<0.05$. No multiple comparison correction since only one comparison per dimension was carried out. Means displayed, standard errors in parentheses. 
Table 6-Group comparisons of perceived competence, benevolence and honesty for policy outcome transparency

\begin{tabular}{|l|lll|lll|}
\hline & \multicolumn{3}{|c|}{ The Netherlands } & \multicolumn{3}{c|}{ South Korea } \\
\hline Dependent & Control & Positive & Negative & Control & Positive & Negative \\
Variable & $\mathbf{N = 3 3}$ & $\mathbf{N = 4 3}$ & $\mathbf{N = 4 8}$ & $\mathbf{N = 1 9}$ & $\mathbf{N = 1 4}$ & $\mathbf{N = 1 7}$ \\
\hline Perceived & 3.15 & 3.23 & 3.07 & 2.93 & 3.23 & 1.87 \\
Competence & $(.05)^{\mathrm{a}, \mathrm{b}}$ & $(.05)^{\mathrm{a}}$ & $(.05)^{\mathrm{b}}$ & $(.16)^{\mathrm{a}}$ & $(.16)^{\mathrm{a}}$ & $(.16)^{\mathrm{b}}$ \\
\hline Perceived & 3.40 & 3.35 & 3.53 & 2.09 & 2.65 & 2.14 \\
Benevolence & $(.05)^{\mathrm{a}}$ & $(.06)^{\mathrm{a}}$ & $(.05)^{\mathrm{a}}$ & $(.17)^{\mathrm{a}}$ & $(.20)^{\mathrm{a}}$ & $(.18)^{\mathrm{a}}$ \\
\hline \multirow{2}{*}{ Perceived Honesty } & 3.17 & 3.15 & 3.21 & 1.81 & 2.42 & 1.89 \\
& $(.05)^{\mathrm{a}}$ & $(.05)^{\mathrm{a}}$ & $(.05)^{\mathrm{a}}$ & $(.15)^{\mathrm{a}}$ & $(.18)^{\mathrm{a}}$ & $(.16)^{\mathrm{a}}$ \\
\hline
\end{tabular}

Rows with unequal superscripts differ significantly at $p<0.05$. No multiple comparison correction since only one comparison per dimension was carried out. Means displayed, standard errors in parentheses. Covariates: sex, age and political preference. 
Appendix A) Survey Items

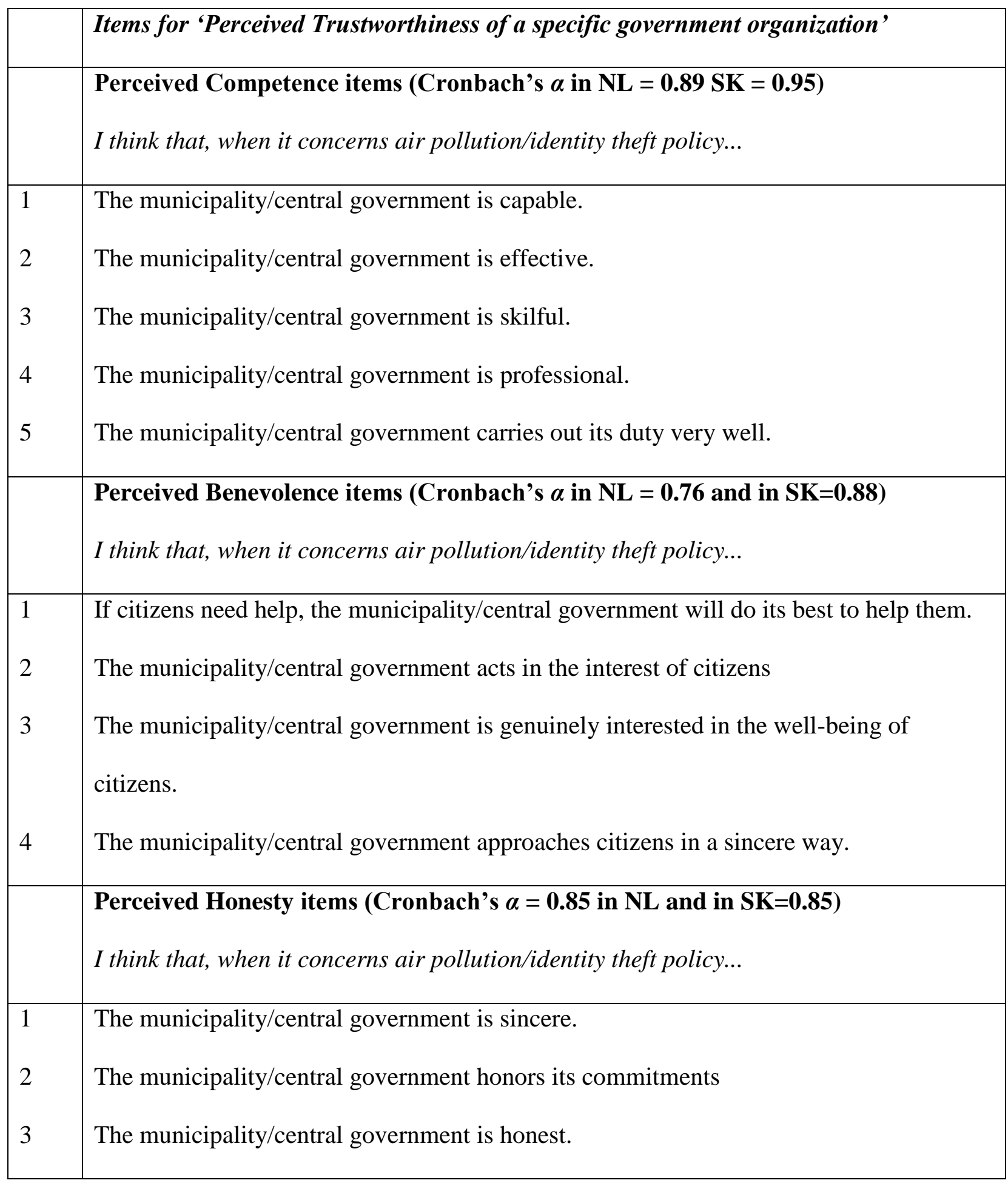

